02,13

\title{
Исследование изолирующей области планарных сверхпроводниковых ҮВСО-структур, формируемых методом задающей маски
}

\author{
(C) Д.В. Мастеров, С.А. Павлов, А.Е. Парафин ॠ, Е.В. Скороходов, П.А. Юнин
}

Институт фризики микроструктур РАН, Нижний Новгород, Россия

๑ E-mail: parafin@ipmras.ru

\begin{abstract}
Рассмотрено развитие нового способа формирования планарных структур на основе высокотемпературного сверхпроводника ҮВСО - метода „задающей маски“. Суть метода заключается в том, что на исходной подложке создается маска, а после осаждения ҮВСО сверхпроводящие элементы оказываются сформированными в заданных локальных окнах маски, а между ними образуются разделительные области. Такие условия роста позволяют получать сверхпроводящие элементы микронного размера с высокими электрофизическими параметрами и гладкой поверхностью.

Исследовано влияние параметров задающей маски из аморфного оксида церия на изолирующие свойства получаемых разделительных областей при изготовлении планарных структур на подложках из сапфира и фианита с эпитаксиальными подслоями оксида церия.
\end{abstract}

Работа поддержана РНФ, проект № 16-19-10478. Использовано оборудование ЦКП „Физика и технология микро- и наноструктур“.

DOI: $10.21883 /$ FTT.2018.11.46646.29NN

Формирование топологии схемы является критически важным этапом при изготовлении планарных структур на основе пленок высокотемпературного сверхпроводника $\mathrm{YBa}_{2} \mathrm{Cu}_{3} \mathrm{O}_{7-d}$ (YBCO), который существенно влияет на их конечные параметры. Это связано с высокой чувствительностью свойств ҮВСО-пленок к внешним воздействиям. Топологию структур на основе пленок ҮВСО формируют различными способами: ионным травлением $[1,2]$, ионной имплантацией $[3,4]$, химическим травлением. Общим во всех указанных методах, несмотря на большое количество модификаций, является то, что сначала на всю поверхность подложки осаждается сверхпроводящая пленка YBCO, а затем формируется топология сверхпроводящего устройства. Нами предложен и развивается новый способ формирования топологии планарных структур на основе высокотемпературного сверхпроводника YВСО - метод „задающей маски“ (3М). Принципиальное отличие метода ЗМ от указанных выше методов заключается в том, что на исходной подложке создается маска, и после осаждения ҮВСО сверхпроводящие элементы оказываются сформированными в заданных окнах (локальных областях) маски, а между ними образуются разделительные области.

Таким образом, метод 3М позволяет формировать сверхпроводящие устройства [5] минуя процесс травления пленок ҮВСО, которые очень чувствительны к внешним воздействиям.

Пленки ҮВСО с наилучшими электрофизическими характеристиками получаются при отклонении интегрального катионного состава от стехиометрии $\mathrm{YBa}_{2} \mathrm{Cu}_{3} \mathrm{O}_{7-d}$ в сторону его обогащения медью. В этой ситуации „лишняя“ медь образует преципитаты $\mathrm{CuO}_{x}$ с высокой плотностью, которые могут достигать микронных размеров. В этой связи формирование структур на основе джозефсоновских контактов и структур с малыми размерами осуществляется на гладких пленках, которые имеют пониженные электрофизические параметры [6]. Нами обнаружен следующий эффект - в условиях роста, когда обеспечиваются высокие электрофизические параметры ҮВСО и на больших, открытых для роста областях в задающей маске плотность преципитатов велика, в локальных областях микронных размеров может вырасти гладкая пленка полностью свободная от преципитатов [7]. Этот эффект открывает возможность получения сверхпроводящих элементов микронного размера не содержащих преципитаты и в то же время обладающих высокими электрофизическими параметрами, что очень важно при изготовлении структур с большим числом элементов [8]. Также этот эффект может быть использован для изготовления многослойных структур и структур для изучения поперечного (вдоль оси $c$ ) транспорта тока в YВСО-пленках [9].

Последовательность формирования сверхпроводниковых структур методом 3М следующая:

- на подложке формируется маска из фоторезиста, после чего при комнатной температуре на подложку напыляется слой аморфного оксида церия $\left(\right.$ coldCeO $\left._{2}\right)$;

- фоторезист вместе с напыленной на него пленкой coldCeO $\mathrm{C}_{2}$ удаляется с подложки в ацетоне в ультразвуковой ванне (lift-off). Таким образом, на подложке образуется ЗМ из аморфной пленки оксида церия, в которой вскрыты окна для последующего формирования в них сверхпроводящих элементов; 
- в завершении на подложку осаждается ҮВСО при температуре эпитаксиального роста. В результате, в окнах маски, на поверхности исходной подложки, получаются сверхпроводящие элементы заданного рисунка, а между ними - разделительные области.

В работе [10] метод ЗМ был нами опробован на подложках $\mathrm{Al}_{2} \mathrm{O}_{3}$, а в качестве материала ЗМ использовался аморфный оксид церия. Пленки YВСО, осажденные в используемых нами режимах магнетронного напыления непосредственно на $\mathrm{Al}_{2} \mathrm{O}_{3}$, представляют собой изолятор. Поэтому после формирования ЗМ на подложку $\mathrm{Al}_{2} \mathrm{O}_{3}$ осаждался оксид церия при температуре $T_{d}=900^{\circ} \mathrm{C}(\operatorname{hotCeO})$. В результате этого в окнах маски формировался подслой эпитаксиального оксида церия $\left(\right.$ еріCеО $\left.\mathrm{C}_{2}\right)$ с характерной величиной полуширины кривой качания рентгеновского отражения $\Delta \omega=0.25-0.50^{\circ}$, a в областях, где на подложке осталась пленка coldCeO $\mathrm{C}_{2}$ - нетекстурированный поликристалл $\mathrm{CeO}_{2}$. Для создания задающей маски на подложках $\mathrm{Al}_{2} \mathrm{O}_{3}$ использовался слой coldCeO 2 толщиной $50-100 \mathrm{~nm}$. Толщина подслоя еріСеО $\mathrm{C}_{2}$ в окнах маски составляла 40-50 nm. На рис. 1, $a$ показана область границы между окном в маске для формирования сверхпроводящего
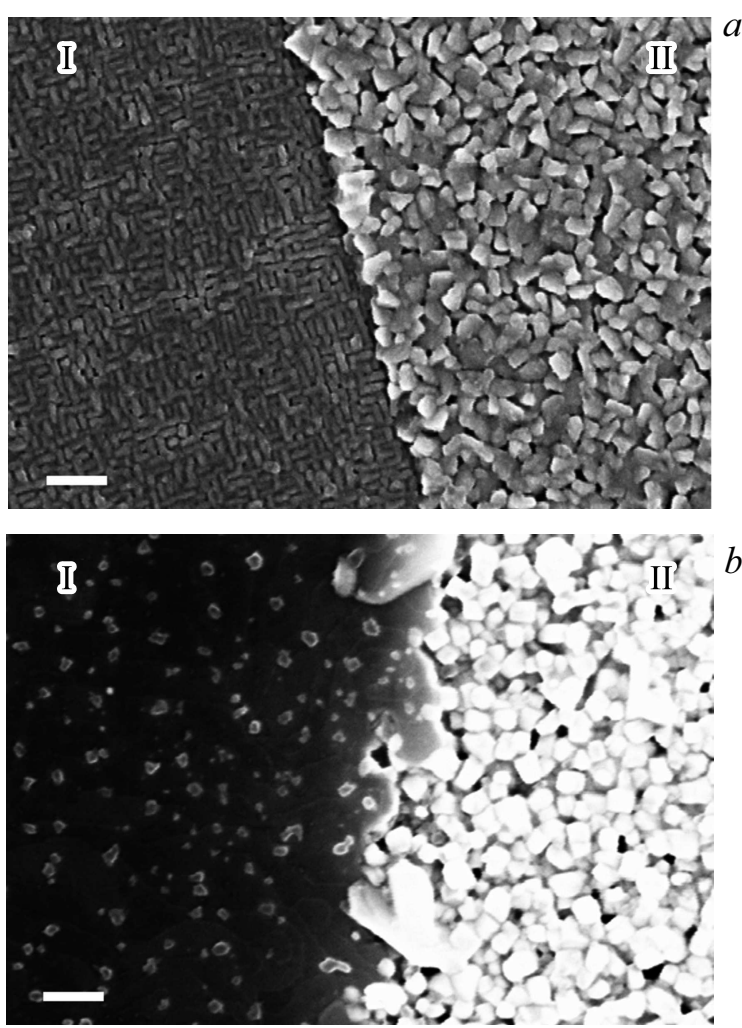

Pис. 1. SEM-изображения поверхности образцов на подложке $\mathrm{Al}_{2} \mathrm{O}_{3}$. $a$ - образец после осаждения слоя hotCeO $\mathrm{O}_{2}$ : область $\mathrm{I}$ - эпитаксиальный подслой $\mathrm{CeO}_{2}$ на $\mathrm{Al}_{2} \mathrm{O}_{3}$, область II - поликристаллический $\mathrm{CeO}_{2} . b-$ тот же образец после осаждения YВСО: область I - сверхпроводящая пленка YВСО, область II - изолятор. Увеличение - 300000 раз, метка $-100 \mathrm{~nm}$.
Таблица 1. Характеристики ҮВСО-мостиков, полученных на подложке $\mathrm{Al}_{2} \mathrm{O}_{3}$-еріCeO $\mathrm{C}_{2}-$ coldCeO $\mathrm{O}_{2}$ при различной толщине слоя аморфного оксида церия. ( $\rho-$ удельное сопротивление при комнатной температуре, $T_{c}-$ критическая температура, $J_{c}$ - плотность критического тока при $T=77 \mathrm{~K}, \gamma-$ отношение удельных сопротивлений при комнатной температуре и при $T=100 \mathrm{~K}$ )

\begin{tabular}{c|c|c|c}
\hline $\begin{array}{c}\text { Толщина слоя } \\
\text { coldCeO }\end{array}, \mathrm{nm}$ & 0 & 20 & 100 \\
\hline$\rho, \mu, \mathrm{Ohm} \cdot \mathrm{cm}$ & 360 & 390 & 720 \\
$T_{c}, \mathrm{~K}$ & 90.5 & 90.5 & 89.0 \\
$J_{c}, \mathrm{MA} / \mathrm{cm}^{2}$ & 3.1 & 2.9 & 0.63 \\
$\gamma=\rho_{300 \mathrm{~K}} / \rho_{100 \mathrm{~K}}$ & 3.19 & 3.18 & 2.84
\end{tabular}

элемента и разделительной областью. Та же область подложки после осаждения ҮВСО показана на рис. $1, b$.

В настоящей работе рассмотрено влияние параметров ЗМ из аморфного оксида церия на свойства получаемых разделительных изолирующих областей на сапфировых и фианитовых подложках, на всю поверхность которых был предварительно нанесен подслой эпитаксиального оксида церия $\left(\mathrm{Al}_{2} \mathrm{O}_{3}\right.$-еріCеO $\mathrm{Ce}_{2}$ и YSZ-epiCeO $\left.\mathrm{Y}_{2}\right)$. На таких подложках, в отличие от подложек $\mathrm{Al}_{2} \mathrm{O}_{3}$ без подслоя, в стандартных режимах магнетронного напыления растут высококачественные сверхпроводящие пленки.

Оксид церия наносился распылением керамической мишени состава $\mathrm{CeO}_{2}$ излучением эксимерного лазера LPX 200 (длина волны $\lambda=248 \mathrm{~nm}$ ) в атмосфере кислорода при давлении $P=20$ Ра. Пленки ҮВСО осаждались методом магнетронного напыления в стандартных условиях для эпитаксиального роста ҮВСО [11] при температуре подложки $T_{d}=800-850^{\circ} \mathrm{C}$ и давлении газовой смеси $\operatorname{Ar}(50 \%) / \mathrm{O}_{2} P=75 \mathrm{~Pa}$. Рентгенодифракционный анализ полученных пленок проводился на дифрактометре Bruker D8 Discover. Поверхностная морфология образцов исследовалась методом сканирующей электронной микроскопии (SEM) на автоэмиссионном растровом электронном микроскопе Supra 50VP (изготовитель ZEISS, Германия). Для получения SEM-изображения диэлектрических поверхностей исследуемые образцы покрывались тонким (5-10 nm) слоем ванадия. Серебряные контакты к образцам наносились термическим испарением через металлическую маску. Электрические измерения проводились стандартным четырех зондовым методом.

Особенности, возникающие при формировании рисунка методом 3М на подложках, пригодных, в отличие от сапфира без подслоя, для эпитаксиального роста пленок YBCO, видны на следующем примере. На подложке $\mathrm{Al}_{2} \mathrm{O}_{3}$ описанным выше способом была сформирована задающая маска для получения мостиков шириной 4 и $10 \mu \mathrm{m}$. После осаждения на поверхность образца слоя hotCeO $\mathrm{C}_{2}$ в окнах маски образовалась подложка $\mathrm{Al}_{2} \mathrm{O}_{3}$-еріCеO $\mathrm{CeO}_{2}$ (см. рис. 1, $a$, область I). Далее, на третью часть подложки через маску была напылена 
Таблица 2. Характеристики образцов с различной толщиной слоя coldCeO ${ }_{2}$ на подложках $\mathrm{Al}_{2} \mathrm{O}_{3}-\mathrm{epiCeO}_{2}$. $\left(I_{c}-\right.$ критический ток при $T=77 \mathrm{~K}$. Ширина тестового мостика $4 \mu \mathrm{m}$ )

\begin{tabular}{c|c|c|c|c|c}
\hline № & $\begin{array}{c}\text { Толщина слоя } \\
\text { соldСeO2, }\end{array}$ & $\begin{array}{c}\text { Эффективная } \\
\text { толщина ҮВСО, } \mathrm{nm}\end{array}$ & $\begin{array}{c}\text { Сопротивление } \\
\text { между чипами } \\
\text { при } T=300 \mathrm{~K}, \mathrm{Ohm}\end{array}$ & $\begin{array}{c}\text { Параметры } \\
\text { областей } \\
\text { между чипами }\end{array}$ & $\begin{array}{c}\text { Параметры } \\
\text { мостиков }\end{array}$ \\
\hline 1 & 100 & 80 & $R=8.7$ & $\begin{array}{c}T_{c}=89 \mathrm{~K} \\
I_{c}=194 \mathrm{~mA}\end{array}$ & $\begin{array}{c}\text { Чипы } \\
\text { закорочены }\end{array}$ \\
\hline 2 & 200 & 80 & $R=41.0$ & $\begin{array}{c}T_{c}=78 \mathrm{~K} \\
I_{c}=1 \mathrm{~mA}\end{array}$ & $\begin{array}{c}\text { Чипы } \\
\text { закорочены }\end{array}$ \\
\hline 3 & 1200 & 200 & $R=4 \cdot 10^{6}$ & $\begin{array}{c}R>1.5 \cdot 10^{8} \mathrm{Ohm} \\
\text { при } T=77 \mathrm{~K}\end{array}$ & $\begin{array}{c}T_{c}=90.7 \mathrm{~K} J_{c}=3.0 \mathrm{MA} / \mathrm{cm}^{2} \\
\text { при } 77 \mathrm{~K}\end{array}$
\end{tabular}

пленка coldCeO 2 толщиной $100 \mathrm{~nm}$, на другую треть пленка coldCeO 2 толщиной $20 \mathrm{~nm}$, на оставшуюся треть пленка coldCeO $\mathrm{C}_{2}$ не напылялась. Затем на всю подложку напылили слой ҮВСО. Объем осажденного материала ВТСП характеризуется толщиной эпитаксиальной сверхпроводящей пленки YBCO, выросшей на поверхности эпитаксиального оксида церия. В областях подложки, где присутствует coldCeO $\mathrm{C}_{2}$, осаждается такое же количество YВСО, и поэтому для характеризации количества материала, осажденного на всю подложку, мы введем эффективную осаждаемую толщину ҮВСО. В данном случае на всю подложку осаждался слой ҮВСО с эффективной толщиной $400 \mathrm{~nm}$. Далее были сформированы серебряные контакты к мостикам. Характеристики полученных мостиков представлены в табл. 1. Как видно из табл. 1., небольшая толщина cold $\mathrm{CeO}_{2}$ на подложках $\mathrm{Al}_{2} \mathrm{O}_{3}$-еріCеO 2 не препятствует росту сверхпроводящей пленки YВСО. Следовательно, сформировать задающую маску на подложке $\mathrm{Al}_{2} \mathrm{O}_{3}$-еріCеO $\mathrm{Ce}_{2}$ простым нанесением тонкого слоя cold $\mathrm{CeO}_{2}$ не удастся.

Поэтому нами были рассмотрены два варианта формирования ЗМ с высоким сопротивлением разделительной области: первый - увеличение толщины слоя coldCeO $\mathrm{C}_{2}$, второй - формирование $3 \mathrm{M}$ с помощью двухслойной структуры coldCeO $\mathrm{C}_{2}+$ hot $\mathrm{CeO}_{2}$.

Для определения величины сопротивления разделительных областей с 3М различной толщины, на подложках $\mathrm{Al}_{2} \mathrm{O}_{3}$-еріCеО $\mathrm{C}_{2}$ были изготовлены образцы с толщиной coldCeO $\mathrm{C}_{2}$ 100, 200 и $1200 \mathrm{~nm}$. Затем на приготовленные образцы осаждали ҮВСО с эффективной толщиной 80,80 и $250 \mathrm{~nm}$, соответственно. Параметры изготовленных структур указаны в табл. 2. Сопротивление между чипами, содержащими тестовые мостки, характеризует изолирующие свойства разделительной области. Ширина сверхпроводящей области чипа равнялась $800 \mu \mathrm{m}$, расстояние между соседними чипами - $100 \mu \mathrm{m}$. В случае толщин coldCeO 100 и $200 \mathrm{~nm}$ даже при небольшой эффективной толщине осаждаемого ҮВСО - $80 \mathrm{~nm}$ разделительная область обладает сверхпроводящими свойствами. Для образца с толщиной 3М $1200 \mathrm{~nm}$ при эффективной толщине YВСО
$250 \mathrm{~nm}-$ сопротивление между чипами при $T=77 \mathrm{~K}$ составило величину $R>1.5 \cdot 10^{8} \mathrm{Ohm}$. Таким же оказалось сопротивление между чипами при $T=77 \mathrm{~K}$ и толщине coldCeO $200 \mathrm{~nm}$ для аналогичных структур на подложках YSZ-epiCeO 2 .

На рис. 2, a показана морфология поверхности слоя coldCeO $\mathrm{C}_{2}$ толщиной $1200 \mathrm{~nm}$ на подложке $\mathrm{Al}_{2} \mathrm{O}_{3}$-еріCеО 2 . Видно, что слой представляет собой

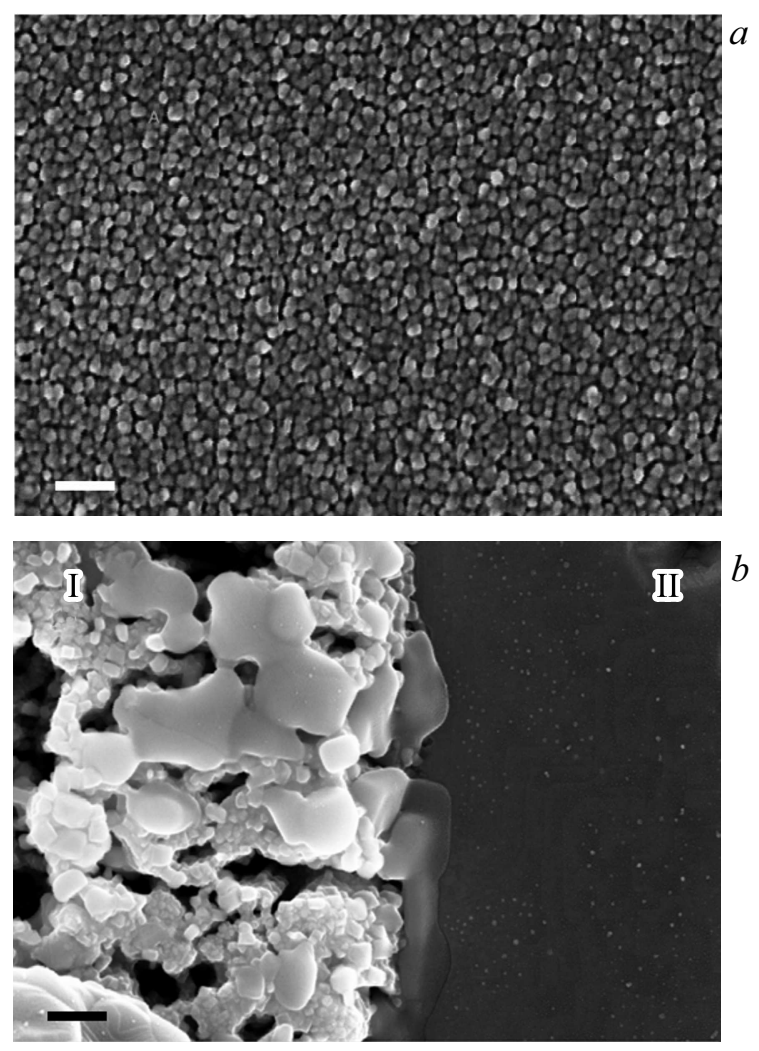

Рис. 2. SЕМ-изображения поверхности образцов. $a-$ поверхность слоя coldCeO $\mathrm{O}_{2}$ толщиной $1200 \mathrm{~nm}$ на подложке $\mathrm{Al}_{2} \mathrm{O}_{3}-$-еріCеО ${ }_{2}$. Увеличение -300000 раз, метка $-100 \mathrm{~nm}$. $b$ - граница между сверхпроводящим мостиком (область II) и разделительной областью (область I) после осаждения ҮВСО. Увеличение - 150000 раз, метка - $200 \mathrm{~nm}$. 

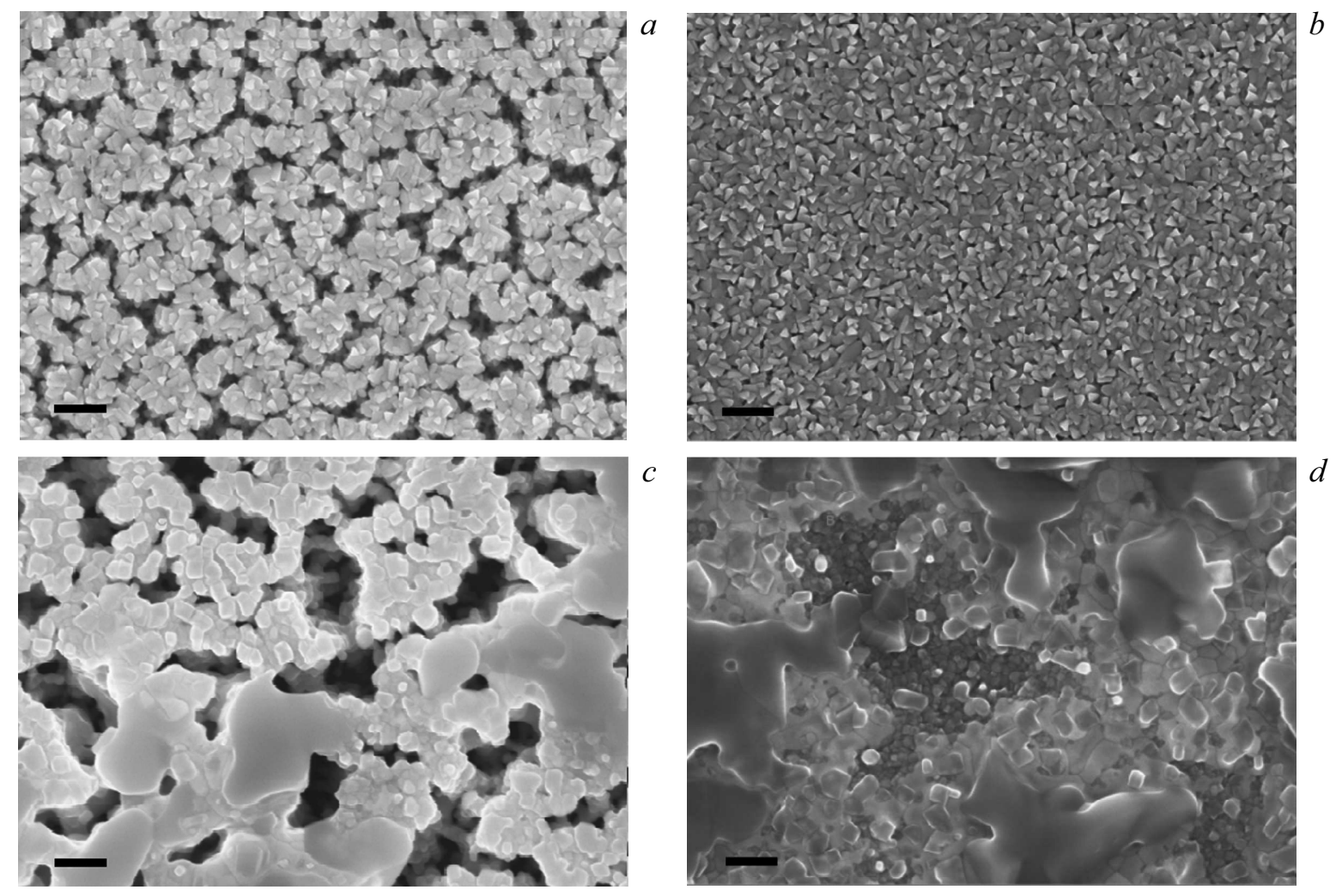

Рис. 3. SEM-изображения поверхности двухслойных структур coldCeO $\mathrm{C}_{2}+\mathrm{hotCeO}_{2}$ с разными толщинами слоя соldCеО ${ }_{2}$ на подложке $\mathrm{Al}_{2} \mathrm{O}_{3}$-еріCеО $\mathrm{C}_{2}$ до $(a, b)$ и после $(c, d)$ осаждения YBCO. $(a, c)$ - толщина слоя coldCeO $1200 \mathrm{~nm} .(b, d)-$ толщина слоя coldCeO $100 \mathrm{~nm}$. Увеличение - 150000 раз, метка $-200 \mathrm{~nm}$.

сплошную зернистую пленку из частиц размером 30-40 nm. На рис. 2, $b$ показано SEM-изображение поверхности образца после осаждения ҮВСО на подложку с ЗМ-толщиной $1200 \mathrm{~nm}$. Как можно видеть, морфология разделительной области (I) изменилась коренным образом: сформировалась очень развитая, содержащая разрывы поверхность. Поверхность образцов с меньшей толщиной слоя coldCeO 2 имеет сходную морфологию (SEM-фото не приведены).

Рентгенофазовый анализ структуры, полученной в условиях, аналогичных условиям формирования разделительной области в образце с ЗМ-толщиной $1200 \mathrm{~nm}$ и эффективной толщиной $\mathrm{YBCO} 200 \mathrm{~nm}$ (рис. 2, $b$, область I), показал наличие сверхпроводящей эпитаксиальной фазы $\mathrm{YBa}_{2} \mathrm{Cu}_{3} \mathrm{O}_{7-d}$ в количестве около десяти процентов от количества сверхпроводящей фазы, сформировавшейся на мостиках. По-видимому, даже при толщине слоя coldCeO $21200 \mathrm{~nm}$ глубина части разрывов достигает подложки $\mathrm{Al}_{2} \mathrm{O}_{3}-\mathrm{epiCeO}_{2}$, и там растет сверхпроводящая фаза ҮВСО, состоящая из отдельных островков. Такие островки могут закорачивать сверхпроводящие элементы при изготовлении схем с малыми расстояниями между ними. Отметим, что на пленке сверхпроводника вблизи границы с изолирующей областью преципитаты отсутствуют (см. рис. $2, b$, область II) и она имеет совершенную гладкую поверхность.
Нами также была рассмотрена возможность формирования $3 \mathrm{M}$ в виде двухслойной структуры: coldCeO $\mathrm{Ce}_{2}+$ hotCeO $\mathrm{O}_{2}$. (Разделительная область такой структуры (см. рис. 1, $a$, область II), образуется при использовании метода ЗМ для подложек $\mathrm{Al}_{2} \mathrm{O}_{3}$ перед осаждением YВСО.) Для этого на подложку $\mathrm{Al}_{2} \mathrm{O}_{3}$-еріCеO последовательно, через маску, осаждали coldCeO 2 таким образом, чтобы на ней образовались три области с толщинами слоя coldCeO 2 100, 500 и $1200 \mathrm{~nm}$. Затем на всю подложку был напылен слой hotCeO 2 толщиной $50 \mathrm{~nm}$, после чего подложка была разрезана на две части.

Одна половина подложки, после напыления ванадия, была использована для получения SEM-изображений. На рис. 3,a показана область с толщиной слоя coldCeO $1200 \mathrm{~nm}$. Поверхность области с толщиной слоя coldCeO $500 \mathrm{~nm}$ имеет сходную морфологию (SEM-фото не приведено), но площадь разрывов больше. На рис. 3, $b$ показана область с толщиной слоя coldCeO 2 $100 \mathrm{~nm}$. Морфология этой области подобна структуре поликристаллического $\mathrm{CeO}_{2}$ на сапфире (см. рис. 1, $a$, область II) и резко отличается от морфологии двух других областей. На SEM-фото видно достаточно плотное покрытие из гранулированных зерен. Размер видимых разрывов порядка $10-50 \mathrm{~nm}$. Латеральный размер зерен пленки 40-80 $\mathrm{nm}$. 
Таблица 3. Сопротивление между контактами в образцах

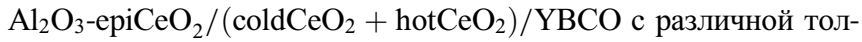
щиной слоя coldCeO 2 при комнатной $(T=300 \mathrm{~K})$ температуре и при $T=77 \mathrm{~K}$

\begin{tabular}{c|c|c|c}
\hline $\begin{array}{c}\text { Толщина слоя } \\
\text { coldCeO }_{2}, \mathrm{~nm}\end{array}$ & 1200 & 500 & 100 \\
\hline$R(T=300 \mathrm{~K}), \mathrm{Ohm}$ & $1.5 \cdot 10^{8}$ & 145 & $1.5 \cdot 10^{4}$ \\
$R(T=77 \mathrm{~K}), \mathrm{Ohm}$ & $1.5 \cdot 10^{8}$ & 24 & $1.5 \cdot 10^{8}$
\end{tabular}

На вторую половину подложки напылили слой ҮВСО с эффективной толщиной $160 \mathrm{~nm}$. На рис. $3, c, d$ представлены SEM-изображения областей с толщиной слоя coldCeO $_{2} 100 \mathrm{~nm}$ и $1200 \mathrm{~nm}$ после осаждения YВСО. В табл. 3. приведены результаты измерений сопротивления $R$ между контактами, напыленными через маску на все три области подложки. Размеры контактов 400-600 $\mu \mathrm{m}$, расстояние между контактами $250 \mu \mathrm{m}$.

Из сравнения данных табл. 3. и данных по сопротивлению разделительной области в случае однослойной $3 \mathrm{M}$ (табл. 2), а также сравнения структуры поверхностей, представленных на рис. $2, b$, область I и рис. $3, c$, можно заключить, что напыление тонкого $(50 \mathrm{~nm})$ слоя hot $\mathrm{CeO}_{2}$ слабо влияет на свойства разделительной области с толщиной слоя coldCeO $1200 \mathrm{~nm}$. В то же время, напыление hot $\mathrm{CeO}_{2}$ на слой coldCeO $\mathrm{C}_{2}$ толщиной $100 \mathrm{~nm}$ приводит к образованию плотной, без разрывов, пленки поликристаллического $\mathrm{CeO}_{2}$ (рис. $3, b$ ). В процессе осаждения ҮВСО разрывы в этой области также не образуются (рис. $3, d$ ). В результате получается разделительная область с высоким сопротивлением (табл. 3.). Интересно отметить, что при промежуточной толщине слоя cold $\mathrm{CeO}_{2}$, равной $500 \mathrm{~nm}$, сопротивление разделительной области мало.

Далее, на подложках $\mathrm{Al}_{2} \mathrm{O}_{3}$-еріCеО $\mathrm{C}_{2}$ методом двухслойной задающей маски были изготовлены мостики шириной $10 \mu \mathrm{m}$. Толщина слоя coldCeO ${ }_{2}$ на двух образцах составляла 1200 и $100 \mathrm{~nm}$, слоя hotCeO $\mathrm{C}_{2}-$ $50 \mathrm{~nm}$, пленки $\mathrm{YBCO}-160 \mathrm{~nm}$. Сопротивление между чипами при комнатной и азотной температурах для обоих образцов превысило $1.5 \cdot 10^{8} \mathrm{Ohm}$, плотность критического тока на сверхпроводящих мостиках составила $3 \cdot 10^{6} \mathrm{~A} / \mathrm{cm}^{2}$.

Результаты проведенных экспериментов позволяют сделать следующие выводы. Метод задающей маски был успешно использован для изготовления тестовых структур на подложках $\mathrm{Al}_{2} \mathrm{O}_{3}$-epiCeO $\mathrm{C}_{2}$ и YSZ-epiCeO $\mathrm{C}_{2}$, которые, в отличие от $\mathrm{Al}_{2} \mathrm{O}_{3}$, пригодны для роста высококачественных эпитаксиальных пленок YВСО.

Высокое сопротивление разделительных областей на этих подложках было получено при толщине однослойной задающей маски (пленки cold $\mathrm{CeO}_{2}$ ) равной $1200 \mathrm{~nm}$.

Формирование задающей маски на подложках $\mathrm{Al}_{2} \mathrm{O}_{3}$-еріCеO структуры: coldCeO $_{2}+$ hotCeO $_{2}$ показало, что ee морфология существенным образом зависит от толщины слоя coldCeO ${ }_{2}$. При толщинах этого слоя в 500 и $1200 \mathrm{~nm}$ морфология ЗМ характеризуется резкой неоднородностью и разрывами, и практически совпадает с морфологией однослойной задающей маски. В тоже время, при толщине слоя coldCeO $100 \mathrm{~nm}$, задающая маска представляет собой плотное покрытие из гранулированных зерен $\mathrm{CeO}_{2}$. В результате, высокое сопротивление разделительных областей в тестовых структурах с двухслойной $3 \mathrm{M}$ было получено в случае толстого $(1200 \mathrm{~nm})$ и тонкого $(100 \mathrm{~nm})$ слоя cold $\mathrm{CeO}_{2}$. При промежуточной $(500 \mathrm{~nm})$ толщине слоя coldCeO сопротивление разделительных областей оказалось на несколько порядков ниже, чем в двух других вариантах как при комнатной, так и при азотной температурах.

\section{Список литературы}

[1] E. Il'ichev, L. Dörrer, F. Schmidl, V. Zakosarenko, P. Seidel, G. Hildebrandt. Appl. Phys. Lett. 68, 708, (1996).

[2] M.I. Faley, U. Poppe, K. Urban, V.Yu. Slobodchikov, Yu.V. Maslennikov, A. Gapelyuk, B. Sawitzki, A. Schirdewan. Appl. Phys. Lett. 81, 2406, (2002).

[3] W. Lang, M. Marksteiner, M.A. Bodea, K. Siraj, J.D. Pedarnig, R. Kolarova, P. Bauer, K. Haselgrübler, C. Hasenfuss, I. Beinik, C. Teichert. Nucl. Instrum. Meth. Phys. Res. 272, 300, (2012).

[4] M. Malnou, C. Feuillet-Palma, C. Ulysse, G. Faini, P. Febvre, M. Sirena, L. Olanier, J. Lesueur, N. Bergeal. J. Appl. Phys. 116, 074505 (2014)

[5] D.V. Masterov, A.E. Parafin, L.S. Revin, A.V. Chiginev, E.V. Skorokhodov, P.A. Yunin, A.L. Pankratov. Supercond. Sci. Technol., 30, 025007, (2017).

[6] Ceraco ceramic coating GmbH. Data sheet HTS coatings. http://www.ceraco.de/hts-films.

[7] L.S. Revin, A.L. Pankratov, A.V. Chiginev, D.V. Masterov, A.E. Parafin, S.A. Pavlov. Proc. of 16th (ISEC'2017) DOI: 10.1109/ISEC.2017.8314206.

[8] A.M. Klushin, M. He, S.L. Yan, N. Klein. Appl. Phys. Lett. 89, 232505, (2006).

[9] P.V. Komissinski, E. Il'ichev, G.A. Ovsyannikov, S.A. Kovtonyuk, M. Grajcar, R. Hlubina, Z. Ivanov, Y. Tanaka, N. Yoshida, S. Kashiwaya. Europhys. Lett., 57, 585 (2002).

[10] Д.В. Мастеров, С.А. Павлов, А.Е. Парафин, П.А. Юнин. ПЖТФ 42, 82, (2016).

[11] Ю.Н. Дроздов, Д.В. Мастеров, С.А. Павлов, А.Е. Парафин, П.А. Юнин. ЖТФ 85, 109, (2015).

Редактор К.В. Емцев 